\title{
PRIMEIRO ENCONTRO DE AEDES (STEGOMYIA) ALBOPICTUS (SKUSE) NO ESTADO DE SÃO PAULO (BRASIL).
}

\author{
Marylene de Brito* \\ Gisela R.A.M. Marques * \\ Cristiano C.A. Marques * \\ Rosa Maria Tubaki *
}

A Superintendência de Controle de Endemias (SUCEN), por intermédio do Programa de Controle da Febre Amarela e Dengue, desenvolve atividades no sentido de detectar a presença de Aedes aegypti (Linnaeus), no Estado de São Paulo. Considerando a importância de outras espécies de culicídeos na transmissão destas doenças, e a presença de Aedes albopictus (Skuse) nos Estados do Rio de Janeiro, Espírito Santo e Minas Gerais foi intensificado o trabalho de vigilância desse vetor.

Em decorrência desse trabalho, no dia 17 de setembro de 1986, foram encontradas, pela primeira vez, 3 exemplares de larvas de Ae. albopictus (Skuse) no Município de Areias, SP, tendo a identificação sido confirmada pelo Laboratório de Entomologia da Fauldade de Saúde Pública da Uni- versidade de São Paulo. As larvas foram coletadas em recipiente artificial (vaso de plantas) em um cemitério localizado próximo ao Campo Municipal. Outros autores 1,2 também relatam a presença do vetor em recipientes artificiais, em cidades, caracterizando-o secundariamente como de ambiente urbano.

O Município de Areias localizado no Médio Pa. raíba, situa-se a leste do Estado de São Paulo, tendo como acesso principal a rodovia SP-66 (antiga Rio. -São Paulo). Fazem limite com esse município: Queluz, Silveira, Cunha, São José do Barreiro e Resende (RJ).

Após esse encontro, não tem sido mostrada a presença de $A e$ albopictus, pela investigação que vem sendo realizada até o momento.

\section{REFERENCIAS BIBLIOGRAFICAS}

1. FORATTINI, O.P. Identificação de Aedes (Stegomyia) albopictus no Brasil. Rev.Saúde públ., S.Paulo, 20 : 244-5, 1986.

2. HUANG, Y.M. Contribution to the mosquito fauna of Southeast Asia. XIV - The subgenus Stegomyia of Aedes in southeast Asia. I. The Scutellaris group of species. Contrib. Amer. Ent. Inst., 9(1), 1972.

Recebido para publicaçāo em 14/10/1986

Aprovado para publicação em 20/10/1986

* Da Superintendência de Controle de Endemias (SUCEN) - Rua Paulo Souza, 166 - 01027 - São Paulo, SP - Brasil. 